\title{
Los destinos turísticos y su llamado a la gestión desde la planificación local. Un acercamiento al producto turístico de la provincia de Gutiérrez
}

\section{Tourist destinations and their call for management from local planning. An approach to the tourist product of the province of Gutierrez}

\author{
Sandra Milena Sanchez Castellanos* \\ Corporación Unificada Nacional de Educación Superior - CUN, Colombia \\ José Fabían Suárez Salazar \\ Universidad Pedagógica y Tecnológica de Colombia, Colombia
}

\section{RESUMEN}

Se recopila los elementos que dieron paso tanto a la construcción del Producto Turístico de la Provincia de Gutiérrez en el departamento de Boyacá (Colombia), como a su gestión, desde la planeación estratégica del desarrollo turístico en el territorio. Este escenario se genera luego de los acontecimientos que impulsaron, a este destino, a replantear los diferentes sectores que convergen en la actividad turística característica, desde la organización de los actores clave del territorio hasta la consolidación del producto insignia del municipio.

Se plantea una visión del producto turístico, desde la planificación turística local y su interacción entre los sectores que, impulsados especialmente por el sector privado, rediseñaron la actividad. Proceso llevado a cabo mediante el desarrollo de cuatro proyectos relacionados con el diseño de producto, estudio de mercados, caracterización de prestadores de servicios y plan de promoción. Lo que inició con el desarrollo de talleres con la comunidad local donde se identificaron actores clave, se valoraron los sitios de interés turístico, infraestructura y superestructura turística, así como la creación de un plan de acción para el desarrollo del producto turístico provincial.

Palabras clave: comunidad local, destino turístico, gestión turística, mercadeo turístico, planificación turística local, prestadores de servicios turísticos, producto turístico, profesionales del turismo. 


\begin{abstract}
This article compiled the elements that gave way to both the construction of the Tourist Product of the Province of Gutierrez in the department of Boyaca (Colombia) and its management, from the strategic planning of tourism development in the territory. This scenario was generated after the events that prompted this destination to rethink the different sectors that converge in the characteristic tourist activity; from the organization of the key actors in the territory, to the consolidation of the municipality's flagship product

A vision of the tourism product was proposed, from the local tourism planning and its interaction between the sectors that, especially driven by the private sector, redesigned the activity. This process was carried out through the development of four projects related to product design, market research, characterization of service providers, and a promotion plan, starting with the development of workshops with the local community where key actors were identified, the sites of tourist interest, infrastructure, and tourist superstructure were valued, as well as the creation of an action plan for the development of the provincial tourist product.
\end{abstract}

Keywords: local community, tourism destination, tourism management, tourism marketing, local tourism planning, tourism service providers, tourism Product, tourism professionals.

\title{
Introducción
}

Para el año 2016 se generó uno de los sucesos más neurálgicos en el desarrollo del turismo de la provincia de Gutiérrez, con el cierre del principal atractivo turístico de la región, el Parque Nacional Natural El Cocuy, ubicado entre los municipios de El Cocuy, Güicán de la Sierra y Chita en el Departamento de Boyacá. Parte de los causales que motivaron el cierre obedecían a diferentes inconformidades entre la comunidad indígena U'wa presente en el territorio, líderes campesinos de la zona y el uso turístico que tenía la sierra promovido por los prestadores de servicios turísticos (La pelea por EL Cocuy, 2017).

Este acontecimiento que se extendió por más diez meses entre los años 2016 y 2017, impactó de manera considerable en el desarrollo económico del territorio, no solo de los municipios previamente mencionados, sino también de los demás municipios pertenecientes a la provincia, dando paso al cierre de diferentes establecimientos, lo que representó en cifras cerca de 20000 millones de pesos colombianos en pérdidas (Tunja. \$20.000 millones se han perdido desde el cierre de “El Cocuy", 2017).

Sin embargo, desde el sector privado surgió la iniciativa de atender a la crisis de forma directa, por tanto, si la Sierra Nevada no podía considerarse para la actividad turística ¿cuál sería la motivación para la llegada y permanencia en el destino de viajeros y visitantes? El replantear el futuro de la actividad turística en el territorio, detallar la vocación y reconocer los diferentes elementos que convergen en el mismo para el desarrollo del 
turismo, permitió ver más allá de la sierra y postular un producto turístico innovador en busca de reactivar al sector, realizando así un ejercicio motivado por la comunidad receptora representada por el tejido empresarial de la zona.

En esta dinámica nacen los proyectos: Diseño del Producto Turístico para la Provincia de Gutiérrez (en 2017); Caracterización de los prestadores de servicios turísticos presentes en la Provincia de Gutiérrez, Departamento de Boyacá (en 2017); Diseño de un plan de marketing tradicional que aporte al fortalecimiento de la promoción de la oferta turística de la provincia de Gutiérrez (en 2019); y Diseño de un plan de marketing digital para el fortalecimiento de la oferta turística de la provincia de Gutiérrez (en 2019). En cada uno de ellos aplicando una metodología basada en un proceso de planeación desde lo local, buscando atender los requerimientos de la comunidad implicada como promotores y directos participantes de cada proceso planteado.

\section{El destino desde la provincia}

El cierre de la Sierra Nevada no solo afectó a los municipios de Güicán de la Sierra y El Cocuy, también impactó directamente a los municipios circundantes de la provincia que se veían beneficiados de la actividad turística promovida por este atractivo natural, por tanto, al momento de consolidar un nuevo producto turístico se incluyeron los municipios pertenecientes a la Provincia de Gutiérrez, cada uno de ellos aportando una visión del destino desde sus propias potencialidades y necesidades e involucrando procesos de planificación turística local.

De este modo, hablar desde lo local implica reconocer al territorio como un protagonista, como el que decide por sí mismo basado en sus capacidades. Ochoa y Morales (2016, p. 59), sostienen que lo primordial en el ejercicio de la planificación desde las comunidades es "plantear la actividad desde la escala y la capacidad de la población local", siendo la comunidad la que mejor conoce su realidad. Podría añadirse que uno de los componentes del turismo local apunta a la percepción que se tiene del territorio que ha sido planificado desde adentro, retomar miradas de sus actores y de sus visitantes.

Podría atreverse a hablar de una construcción social que puede hacerse en este territorio y que, llegado el caso, puede aportar a la planificación del mismo. Para Hiernaux-Nicolas $(2002$, p. 9) la construcción social es el "encuentro entre las personas que permite crear escenarios afines a la interpretación del espacio en sí”; el aporte desde esta mirada va más allá del producto mismo en la región que se ofrece, está en la forma en que se percibe y se lleva la región cuando se termina el viaje.

La provincia de Gutiérrez, conformada por los municipios de Chiscas, El Espino, El Cocuy, Guacamayas, Güicán de la Sierra y Panqueba, es una de las trece provincias presentes en el departamento de Boyacá (Colombia), podría decirse que, en compañía de Cundinamarca y Antioquia, es uno de los departamentos con mayor cantidad de municipios en el país, y que ha optado por la división provincial y la articulación de municipios en 
una "dinámica de autogestión desde la ruralidad" (CEPAL, 2016).

El departamento de Boyacá, según la Ordenanza N. 37 de 1991, divide su territorio en provincias, determinando sus respectivas capitales y especificando sus órganos de dirección y administración (Buitrago, 2016). Esta distribución no obedece solamente a la ordenanza, viene de la cooperación entre los municipios, que han facilitado que dicha distribución privilegie un atractivo natural específico, así como un piso térmico concreto, es el caso de Sugamuxi con el Lago de Tota, Lengupá con el valle de frutales y Gutiérrez por la Sierra Nevada. En muchas ocasiones, según Giménez (1999, p. 37) el apego territorial asume un "valor simbólico-expresivo y una carga emocional" conceptos que, evidentemente complementan la definición de territorio y sobresalen en la distribución provincial presente en Boyacá.

Respecto a la pertenencia socioterritorial, Giménez (1999, p. 35) añade que "las personas adquieren una conciencia de pertenencia en común con una entidad social si hacen parte de una colectividad", lo que implica que para alcanzar un nivel de involucramiento sociocultural podría atribuirse, especialmente en este caso, a la crisis que sufrió el sector turístico provocada por el cierre, lo cual se convirtió en el canal de integración entre los actores de la actividad turística desde un enfoque local. Aquellos que se vieron afectados consideraron generar una estrategia integral y coordinada como alternativa ante la crisis, que se evidenció a través de la conformación del Consejo Provincial de Turismo de Gutiérrez, quien toma un papel protagónico en todo el proceso.

\section{El producto turístico desde el enfoque territorial}

El producto turístico se entiende como aquel conglomerado de elementos que convergen en pro de atender a un mercado específico, aparte de ser un amalgamado entre elementos como infraestructura, atractivos turísticos, planta turística, superestructura, uso de tecnologías, nivel de capacitación, segmentos de mercado y componentes de la cadena productiva del turismo (cadena de valor), también presenta tres beneficios al momento de consolidarse y ofertase: los beneficios funcionales desde la satisfacción de necesidades básicas, los beneficios simbólicos desde el estatus y la realización personal y finalmente los beneficios vivenciales o sensoriales desde la experiencia del consumidor (Fernández, 2006).

Desde esta mirada, cada elemento que converge en su composición articula un engranaje de la cadena de valor del mismo y permite generar la sinergia entre lo construido y lo ofertado, ante este escenario, lo propuesto desde la población que se encuentra en el territorio representa un valor específico ya que son ellos quienes conocen su territorio y tienen la capacidad de ofrecerlo de acuerdo a este conocimiento, esa visión favorece a la comunidad local como protagonista en su conformación.

Con esta premisa, como parte de la metodología implementada en el desarrollo del producto turístico, se siguieron los lineamientos propuestos por Ochoa y Morales (2016) quienes, a pesar de no enfocar sus escritos únicamente en el diseño de producto turístico, sí apuestan por el desarrollo del turismo con sus elementos inte- 
gradores desde lo local; en su publicación Tejiendo el Territorio, lineamientos para la construcción del turismo desde lo local, los autores buscan brindar herramientas a las comunidades en la identificación y valoración de sus recursos, para su posterior aprovechamiento y representación por medio del mapa del territorio en concordancia con las necesidades del destino.

Igualmente, en la valoración del territorio se incluyó la metodología presentada en el Manual de Desarrollo de Productos Turísticos presentado por la Comisión Europea de Turismo y la Organización Mundial del Turismo (2013) desde el análisis de variables como los recursos de apoyo, ciclo de vida, posibles competidores, fortaleza del sector privado, sistemas de distribución y percepción del destino en los mercados de origen.

Finalmente, se realizó una valoración de la Matriz FODA propuesta en el documento Asistencia Técnica en Planificación del Turismo (del Ministerio de Comercio, Industria y Turismo [MINCIT] y Grupo Planificación y Gestión del Turismo, 2006), añadiendo elementos de valoración que surgieron propiamente del territorio estudiado, así como la incorporación del árbol de problemas y árbol de objetivos como mecanismos de diagnóstico.

Dicho producto fue construido en cuatro etapas mediante cuatro talleres desarrollados especialmente con los actores clave del territorio, representantes de todos los gremios (hotelero, alimentos y bebidas, guías turísticos e informadores y transporte especial); alcaldías de la provincia y los representantes de parques nacionales. En estos talleres se determinó el rol de cada actor, se valoró el patrimonio existente en la zona, el estado de la infraestructura, tanto turística como complementaria, la superestructura disponible para la gestión y los imaginarios turísticos del territorio, que dieron paso a la conformación de la imagen propuesta para el producto turístico con enfoque destino.

\section{Los prestadores de servicios turísticos, una metodología de caracterización}

Uno de los elementos cruciales al momento de diseñar un producto turístico consiste en considerar a los agentes que convergen en el territorio, especialmente a los del sector privado, entendidos ellos como los prestadores de servicios turísticos (PST) quienes toman un papel muy importante en el desarrollo de la actividad turística, especialmente por su rol en la cadena de valor, entendiéndose como una "secuencia de actividades primarias y de apoyo que resultan fundamentales a nivel estratégico para el rendimiento del sector turístico" (Organización Mundial del Turismo [OMT], 2019, p. 15).

Por tanto, según lo publicado en la Guía para la Caracterización de Prestadores de Servicios Turísticos. Un aporte a la planificación turística local (Granados y Suarez, 2018), los PST pueden caracterizarse teniendo en cuenta dos momentos a saber: para el caso colombiano, son prestadores de servicios turísticos los contemplados en la Ley General de Turismo 2068 (por la que se modifica la Ley 300 de 1996) donde se distinguen 11 categorías específicas (MINCIT, 2020). Bajo esta premisa inicial, en segundo lugar, al caracterizar a estos prestadores, esta guía considera elementos propios del territorio para tal labor, es decir, se podrán caracterizar los 
PST de los municipios según la categoría del mismo, donde en el caso particular de Gutiérrez, sus municipios son categoría 5 y 6 respectivamente, según la Ley 617 de 2000 que categoriza a las entidades territoriales. Se sugiere que en estos casos se tengan en cuenta "todos los establecimientos existentes en el territorio independiente de su inscripción al Registro Nacional de Turismo y su grado de formalización" (Granados y Suarez, 2018, p. 25).

\section{Plan de mercadeo con enfoque en el destino}

Según Ojeda y Marmol (2016) El mercadeo en turismo ha experimentado cambios constantes dados por la globalización, alto nivel de la competencia y la inclusión de conceptos digitales, lo cual permite generar mayor impacto en el reconocimiento de empresas y destinos turísticos. Para alcanzar dicho posicionamiento es necesario contar con planeación y ejecución cuidadosa de estrategias afines a lo esperado en el territorio, que involucre a los agentes responsables en pro del producto elaborado.

Esto debe contar con un esquema detallado cuyo objetivo refleje el verdadero alcance que el destino requiere para su promoción, mediante el diseño y ejecución de planes de mercadeo con enfoque al destino. Este concepto no solo aplica a las empresas, también se constituye como una herramienta para destinos turísticos, esto se ve reflejado en las iniciativas consolidadas en el Plan Sectorial de Turismo de Colombia del MINCIT (2018, p. 20): “Turismo: El propósito que nos une 2018-2022”, aquí, en su línea estratégica denominada Productos turísticos diferenciados y de alto valor, se menciona la incidencia del uso de herramientas de marketing para destinos turísticos en temas relacionados con información y promoción eficiente para la productividad, por medio de estrategias de fortalecimiento y promoción turística nacional e internacional con el óptimo uso de las herramientas de mercadeo y de medición.

Teniendo en cuenta los lineamientos expuestos en el Plan Estratégico de la Provincia -documento construido por la Cámara de Comercio de Duitama en 2018- con enfoque en el destino como resultado de la crisis de ese mismo año, se concibe la idea de desarrollar un plan de mercadeo para recopilar el impacto generado en la imagen del destino que permita conocer a los aliados estratégicos para su promoción y reposicionamiento en el mercado, esto en concordancia tanto con el plan estratégico como con los planes de desarrollo sectorial, departamental y municipal. Esta visión se sustenta debido a que "el diseño de un plan de marketing y sus componentes tiene que ser ideado y combinado de manera coherente y consecuente con la realidad del agente en estudio" (Castro et al., 2017, p. 234); es decir, aludiendo a la realidad de su área de influencia.

Para el Producto Turístico de Gutiérrez se establece un plan de promoción tradicional como un plan de promoción digital, donde en ambos escenarios convergen el análisis interno y el análisis externo del objeto de estudio, privilegiando elementos específicos. En la Tabla 1 se evidencian cada uno de los elementos considerados para este estudio. 


\section{Tabla 1}

Elementos de análisis en el desarrollo de un plan de promoción tradicional y digital

\begin{tabular}{|c|c|c|}
\hline Elementos de análisis & Plan de promoción tradicional & Plan de promoción digital \\
\hline \multirow{9}{*}{ Análisis interno } & \multirow[b]{2}{*}{ 1. Objetivos } & 1. Objetivos, actividades y estrategias \\
\hline & & $\begin{array}{l}\text { 2. Estado actual del uso de promoción, redes socia- } \\
\text { les y plataformas especializadas con enfoque pro- } \\
\text { mocional en el destino. }\end{array}$ \\
\hline & \multirow{3}{*}{$\begin{array}{l}\text { Conclusiones de estudios rea- } \\
\text { lizados (caracterización de } \\
\text { prestadores de servicios tu- } \\
\text { rísticos, diseño de producto, } \\
\text { estudio de mercados) }\end{array}$} & Tipo de perfiles en redes \\
\hline & & 4. Tipo de contenido \\
\hline & & 5. Calidad en los contenidos \\
\hline & \multirow{2}{*}{$\begin{array}{l}\text { Análisis FODA con enfoque } \\
\text { promocional }\end{array}$} & 6. Tipos de publicación \\
\hline & & 7. Pertinencia del contenido \\
\hline & \multirow[t]{2}{*}{ 4. Puntos críticos del análisis } & 8. Análisis FODA \\
\hline & & $\begin{array}{l}\text { 9. Puntos críticos y necesidades detectadas en te- } \\
\text { mas de capacitación. }\end{array}$ \\
\hline
\end{tabular}

1. Microambiente

2. Planes y políticas públicas con enfoque promocional para el turismo

Análisis externo
1. Análisis del sector turístico a nivel nacional, departamental y local con enfoque en medios de promoción.

2. Uso de las TIC en la economía y el sector turístico.

3. Estadísticas de marketing digital en Colombia

4. Uso de redes sociales en el país.

5. Importancia de las redes sociales en la economía.

Nota. Elaboración propia.

El mix digital "se compone de un conjunto de herramientas de publicidad, promoción de ventas, relaciones públicas, venta personal y marketing directo que la empresa utiliza para comunicar de forma persuasiva el valor para el cliente y crear relaciones con él" (Kotler et al., 2011, p. 475). Por tanto, se pone énfasis en el plan de marketing y promoción realizado para la Provincia de Gutiérrez en el departamento de Boyacá, centrado en la planeación y ejecución de estrategias de mix promocional publicitario, mediante actividades relacionadas con marketing tradicional y digital. En el desarrollo del plan promocional tradicional se privilegiaron tres de las cuatro estrategias: (1) de producto, (2) de precio y (3) de promoción desde el mix de mercados, como resultado de este ejercicio, la Tabla 2 recopila los principales alcances de cada estrategia. 


\section{Tabla 2}

Estrategias evaluadas, plan de promoción tradicional aplicado a Gutiérrez

\begin{tabular}{|c|c|c|c|}
\hline Elemento & Estrategia de producto & Estrategia de precio & Estrategia de promoción \\
\hline Objetivo & $\begin{array}{l}\text { Generar reconocimiento de la } \\
\text { oferta turística de la provincia } \\
\text { de Gutiérrez del departamen- } \\
\text { to de Boyacá a nivel regional. }\end{array}$ & $\begin{array}{l}\text { Identificar el nivel promedio } \\
\text { de precios por tipo de servicio } \\
\text { ofrecido en el territorio. } \\
\text { Identificar las características } \\
\text { de calidad en prestadores de } \\
\text { servicios turísticos con más } \\
\text { prestigio en la zona. }\end{array}$ & $\begin{array}{l}\text { Contribuir al fortalecimiento y au- } \\
\text { mento del grado de conocimiento de } \\
\text { la oferta turística de la provincia de } \\
\text { Gutiérrez del departamento de Bo- } \\
\text { yacá a nivel regional, a su vez aportar } \\
\text { a la construcción y mantenimiento } \\
\text { una imagen favorable del destino. }\end{array}$ \\
\hline
\end{tabular}

Creación de material promocional tomando como referencia los 12 sitios de interés turístico y tres rutas diseñadas del producto turístico, Estrategia Gutiérrez "Paraíso entre montañas" que contenga como mínimo, sitios de interés turístico, actividades y paquetes ofrecidos y prestadores de servicios turísticos formales.

1. Diseño y creación del mate-

Actividades rial promocional

2. Validación del material
1. Contextualización desde el estudio de mercados en la variable percepción del costo de servicios.

2. Identificar precio por tipo de servicio.

3. Realizar un promedio del costo del servicio e involucrarlo al material promocional creado.

4. Comparación con precios de destinos similares (alojamiento, paquetes, etc.).

5. Identificar la forma de pago ofrecida por los prestadores de servicio.
1. Identificación de los contactos con agencias de viaje.

2. Visitas a 200 agencias de viajes en los departamentos de Boyacá, Casanare y Cundinamarca.

3. Uso de herramientas de relaciones públicas (participación eventos, charlas).

4. Participación en emisoras regionales.

5. Incentivos: Identificación de porcentaje de ganancia por comisión para agencias externas.

6. Entrega de cortesías ofrecidas por prestadores de servicios turísticos en los eventos mencionados. 
1. Estudios realizados en la

zona

2. Paquetes turísticos ofrecidos

1. Estudio de mercados realizado

2. Estudio de caracterización de prestadores de servicios

1. Material promocional creado

2. Bases de datos turísticos

3. Planillas de trabajo

4. Bases de datos prestadores de servicios

3. Páginas especializadas

5. Imagen promocional del destino

Documento con precios pro- Documento resumen con los siguien-

Material promocional diseñamedios de servicios turísticos tes aspectos: listado de contactos

Producto do y aprobado para su divulgación. ofrecidos en la zona, como aporte al material promocional. comerciales, certificados de participación en eventos, certificado de participación en emisoras.

Nota. Elaboración propia.

En el marco del desarrollo del plan se privilegió la estrategia de plaza (cuarto componente del marketing mix) teniendo en cuenta los resultados del Estudio de Mercados para identificar el perfil del turista de Gutiérrez, documento realizado por la Cámara de Comercio de Duitama en 2018, el cual arrojó que el mercado del territorio se encuentra concentrado en un $80 \%$ en la capital del país, Bogotá, seguido del departamento de Casanare y el departamento de Boyacá especialmente. Ante este escenario, como parte la estrategia de promoción se consideró imperativo conocer la percepción que tenían del destino los PST que actúan como comercializadores ubicados en estas zonas, caso especial las Agencias de viajes operadoras.

En el plan de promoción tradicional, se incorporó el mapa de empatía (Osterwalder y Pigneur, 2010) como herramienta para el análisis de percepción del destino por parte de los administradores y propietarios de las agencias de viaje operadoras seleccionadas para el estudio. Estas agencias, ubicadas dentro y fuera del departamento, fueron seleccionadas directamente siendo estos actores clave, de quienes se esperaba conocer tanto la imagen que tenían del destino, el recibimiento frente a la nueva propuesta de producto y los aspectos relevantes que le permitieran a la provincia, desde su propuesta, mejorar la comercialización del destino, así como las acciones de mejora en los servicios ofertados.

\section{Resultados del ejercicio}

El producto turístico de Gutiérrez fue construido en cuatro etapas mediante talleres con los actores clave del territorio como se evidencia en la Figura 1, entre ellos destacan: hoteleros, restaurantes y servicios complementarios de alimentos y bebidas, guías de turismo, informadores turísticos, transportadores, representación de las alcaldías de los seis municipios, representantes de parques nacionales y las cámaras de comercio gestoras 
de la iniciativa. Estos actores se encuentran consolidados en el Consejo Provincial de Turismo de Gutiérrez, como se había mencionado previamente, cabe destacar que actualmente este consejo es uno de los más importantes del Departamento de Boyacá en cuanto a gestión turística.

\section{Figura 1}

Talleres para la construcción del producto turístico desde la comunidad local

- Identificación de actores clave

- Creación de árbol de problemas y

objetivos.

\section{Taller 1}

\section{Objetivos:}

1. Determinar el rol de

cada actor en el territorio

2. Identificar las

principales limitaciones

del sector turístico en el territorio.

\section{Taller 2}

- Identificación y valoración de sitios de interés turístico.
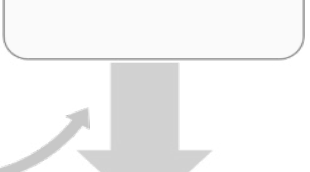

- Identificación Infraestructura y super estructura turística.

\section{Taller 3}

Objetivo:

Valorar el

patrimonio natural,

cultural y su

reconocimiento.

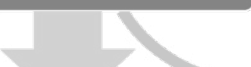

Objetivo:

Determinar aspectos de accesibilidad, conectividad, planes y políticas del sector desde lo local.

\section{Taller 4}

- Identificación de imaginarios turísticos.

Nota. Elaboración propia, 2019.

En el desarrollo de estos talleres se impulsaron especialmente tres objetivos: (1) determinar el rol de cada actor en el territorio desde el diagnóstico del destino, (2) valorar los cuatro elementos del producto presentes en el destino desde cada municipio (patrimonio natural y cultural, infraestructura, superestructura y prestadores), y (3) diseñar la imagen del destino desde el análisis de imaginarios turísticos y la construcción colectiva.

Para el análisis diagnóstico, por medio de la creación de mapas de territorio, el análisis FODA y el resultado de los árboles de problemas, se buscó fortalecer la oferta turística en conjunto, empleando herramientas que apuntaran a la consolidación del territorio como destino turístico, tomando como referencia criterios de planificación y gestión del turismo. Como resultado, se dio paso al diseño de producto turístico para la provincia denominado "Gutiérrez paraíso entre montañas" el cual incorporó en su construcción diferentes atractivos que habían sido opacados en su momento por la prelación que tenía la Sierra Nevada.

El producto se consolidó como la hoja de ruta para el sector turístico de manera prospectiva en el cual, luego de determinar los atractivos y recursos disponibles en cada municipio participante (Figura 1) se crearon tres rutas: (1) “Gutiérrez, Un paraíso entre montañas”, (2) “Paz, Agua y Vida” y (3) “Tejiendo a Gutiérrez”. Las dos primeras rutas recogen los destinos que, luego del análisis, se destacaban por su vocación natural y por tanto 
sus atractivos implicaban un segmento de mercado específico a este tipo de actividades, adicionalmente, estas dos rutas enmarcan diferentes municipalidades donde el ofrecimiento de los servicios se comparte equitativamente entre ellas; cabe destacar que los recursos y atractivos privilegiados en la ruta cuentan con prestadores de servicios específicos en cada zona para su gestión, administración y promoción, como resultado del trabajo cooperativo entre dichos actores.

La tercera ruta, con enfoque cultural, se crea resaltando las potencialidades culturales y patrimoniales del territorio como son su paisaje natural único, sus tradiciones ancestrales como el tejido en lana, la elaboración de la ruana y el alpargate, evidenciadas por medio de talleres demostrativos, tradiciones gastronómicas, la esencia campesina aún viva en estos municipios y su artesanía representada en la cestería en rollo, que cuenta con denominación de origen (Sistema de Información para la Artesanía Siart, 2016). Esta ruta involucra a los seis municipios de la provincia mientras las dos anteriores se distribuyen de acuerdo a distancias y nivel de exigencia de los recursos seleccionados.

\section{Figura 2}

Mapa de atractivos y recursos turísticos de Gutiérrez

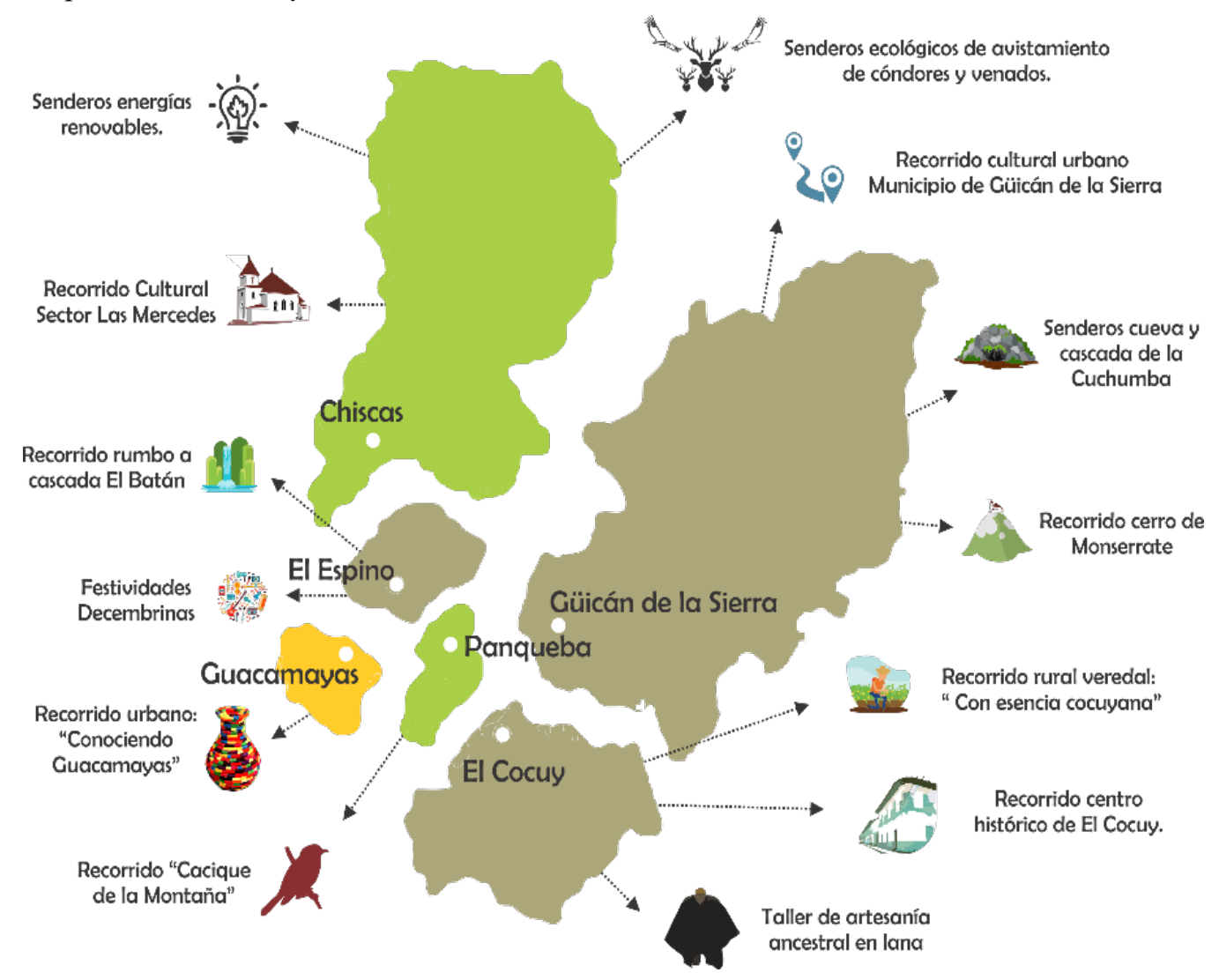

Nota. Cámara de Comercio de Duitama, 2017. 
Se debe resaltar que cada uno de los lugares reflejados en la Figura 2 fue seleccionado por los mismos habitantes del territorio, bajo la guía y criterios de valoración de la metodología propuesta. En cada una de las sesiones se privilegió la incorporación de atractivos y recursos para destinarse a la actividad turística sin afectar la calidad de vida y no deteriorar; es decir, hacer uso del territorio de manera sostenible. Cada uno de estos lugares cuenta tanto con sus guías de turismo como sus informadores turísticos y son reconocidos por las agencias de viajes de la provincia.

Como resultado de la caracterización de prestadores de servicios turísticos luego de las visitas personalizadas, realizadas a los prestadores de los seis municipios contemplados en la guía (Granados y Suárez, 2018) y la aplicación del instrumento de caracterización, se encuentra como resultados sobresalientes lo siguiente: la provincia cuenta con 269 prestadores de servicios turísticos donde 47 de ellos corresponden a establecimientos de alojamiento, 37 a establecimientos de alimentos y bebidas, 4 agencias de viajes, 12 guías profesionales y 171 informadores turísticos no profesionales.

Debido a la recomendación de la guía frente a los prestadores que deberían categorizarse en estos municipios, dicha actividad permitió identificar el nivel de informalidad presente en la provincia, con un $83 \%$, es decir, dichos prestadores no contaban con Registro Nacional de Turismo o matrícula mercantil, siendo este uno de los principales hallazgos en el destino. Esto obliga a desarrollar proyectos de formalización y seguimiento de la actividad. De hecho, de estos prestadores se destaca que el 96\% son microempresas de tipo familiar y dicha oferta genera 473 empleos, de los cuales el $76 \%$ son de tipo ocasional dada la estacionalidad del turismo.

Para desarrollar las actividades de promoción se determinaron dos estrategias fundamentales: marketing tradicional y marketing digital. En cuanto al marketing tradicional se partió de la base misma del mercadeo y se creó un plan, determinando puntos clave que permitieran lograr el objetivo de dar a conocer la zona creando estrategias de producto, precio, promoción y distribución (plaza).

A su vez, se determinaron mediante análisis interno aspectos clave como, cruce entre oferta y demanda, análisis FODA con enfoque en promoción de destino y puntos críticos; en cuanto al análisis externo se determinaron las políticas actuales en temas de promoción y su aporte a la estrategia. Finalmente se realizó un análisis de la competencia del destino, tomando como referencia los picos de nieve como destino turístico en el ámbito internacional, en este caso sobresalen: el Parque Nacional Los Glaciares (Argentina), el Parque Provincial Aconcagua (Argentina) y El Nevado de Salkantay (Perú). Los destinos locales con dicha característica como son el Parque Nacional Natural Sierra de Santa Marta, Parque Nacional Natural el Nevado del Huila y Parque Nacional Natural Los Nevados (Cámara de Comercio de Duitama, 2018, p. 54).

Lo anterior permitió dar paso al marketing mix del destino el cual tuvo como resultado: (1) creación de material promocional de la oferta turística del territorio; (2) visita a 200 agencias de viajes operadoras y mayoristas del departamento de Boyacá, Cundinamarca, Casanare y la ciudad de Bogotá, donde se determinó el grado de conocimiento de estos prestadores frente al destino y facilitó la generación de 60 enlaces comerciales 
para el territorio; (3) participación en medios de comunicación a nivel nacional, entre radio y televisión, se tuvo presencia en cinco emisoras y dos canales de televisión; (4) cinco socializaciones en claustros educativos con estudiantes de últimos semestres en turismo y hotelería; y (5) socialización en los Consejos provinciales de Tundama y Occidente en el departamento de Boyacá.

Este plan dejó como resultado aspectos fundamentales para el territorio respecto a su oferta turística, recopilando la percepción de los administradores y propietarios de las agencias de viajes visitadas, donde se destacan las siguientes apreciaciones según los cuatro parámetros principales del mapa de empatía, como se observa en la Tabla 3.

\section{Tabla 3}

Mapa de empatía, principales hallazgos desde las agencias de viajes, Producto Gutiérrez

\begin{tabular}{|c|c|}
\hline ¿Qué piensa y siente? & ¿Qué ve? \\
\hline $\begin{array}{l}\text { "Algunos servicios son muy costosos y no son de } \\
\text { calidad" (por ejemplo, la guianza). AVBog101* } \\
\text { "Tengo la percepción que es un destino informal } \\
\text { e inseguro por las muertes dentro del PNN" (Ima- } \\
\text { gen del destino). AVBog123 } \\
\text { "Lo que perdimos en la semana santa de } 2016 \\
\text { nunca se recuperó" (secuelas de la crisis). AV- } \\
\text { Boy44 }\end{array}$ & $\begin{array}{l}\text { "Es más fácil enviar gente al Tolima o vender otro destino". AV- } \\
\text { Bog168 } \\
\text { "El trasporte público: Algunas agencias ofertan paquetes con } \\
\text { transporte incluido, las empresas no venden los tiquetes. No hay } \\
\text { cupo, cambian el horario o hasta la empresa, el servicio no es el } \\
\text { mismo entre empresas". AVBoy36 } \\
\text { "Todo se debe operar desde allá, eso nos limita, nosotros trae- } \\
\text { mos turismo nacional e internacional, allá les compramos todo, } \\
\text { tenemos aliados, amigos que nos ayudan, la gente que ofrece el } \\
\text { servicio debería vernos como aliados, pero contrario a eso nos } \\
\text { aprietan". AVBog140 }\end{array}$ \\
\hline ¿Qué oye? & ¿Qué dice y hace? \\
\hline
\end{tabular}

"Nos buscan por el nevado, las consultas acerca del destino son muy frecuentes. (El destino tiene una imagen posicionada)" AVBog108.

"No supe si finalmente ese destino volvió a operar" (la promoción debe fortalecerse). AVCas18; "Buscamos siempre trabajar con los mejores" (bilingüismo y certiAVBog189 ficaciones de calidad). AVBog174

"He escuchado que el PNN lo van a volver a cerrar de nuevo porque el gobierno no cumplió lo que prometió, por eso no me atrevo a ofertar el destino". AVBog99

* La codificación es de acuerdo a la investigación, donde se le asigna este código a cada una de las agencias de viajes (AV) según su ubicación (Casanare = Cas) y el número asignado por visita (18).

Nota. Elaboración propia. 
En cuanto a marketing digital se determinó el estado actual de los medios de promoción digital en el territorio, se realizó una capacitación a los empresarios en la creación y uso de redes sociales y en la creación de contenidos digitales con enfoque promocional. Esto dio paso a la creación de perfiles del destino (@Turismoparacrecer) en redes como Facebook e Instagram con cerca de 130 piezas promocionales, más de 220000 interacciones y cerca de 2200 seguidores hasta diciembre de 2019. El mismo año se creó la página web del destino "Turismo para Crecer" (Url: https://turismoparacrecer.com.co/2, que cuenta con un catálogo digital de la oferta turística del territorio, enmarcado en el producto "Gutiérrez, paraíso entre montañas", recopilando las fotografías de los diferentes atractivos identificados, precios de los servicios, descripción tanto de atractivos como de prestadores y contacto directo con la región, con el fin de generar espacios que permitan aumentar la presencia de la oferta de este importante destino del departamento de Boyacá en medios digitales.

\section{Conclusiones}

Al momento de consolidar el producto turístico en la provincia, uno de los elementos más significativos obedeció a la participación de la comunidad del territorio, tanto prestadores de servicios turísticos como comunidad local se incorporaron a la actividad, evidenciando su intención en participar y así mismo, desde su conocimiento y experticia, seleccionaron recursos y atractivos cuyo potencial es visible desde su propia percepción. Este elemento visibiliza que las mismas comunidades, en este caso Gutiérrez, hallan llegado al punto de diferenciar que el turismo bien planificado apoya y aporta directamente a su desarrollo, pero más importante, desde la gestión de los propios actores y la articulación de más protagonistas en dicha construcción colectiva.

Igualmente, en el rastreo de prestadores existentes en el territorio sigue siendo una constante la informalidad presente en el sector, especialmente en territorios con evidente abandono gubernamental. Gutiérrez es una provincia donde las acciones propiamente del sector público han llegado de manera tardía, a pesar de la importancia que tiene la zona con respecto al atractivo que ha convocado a los visitantes en los últimos años. De hecho, las iniciativas institucionales no reflejan la realidad de los destinos y temas como conectividad y promoción no se relacionan con las necesidades del lugar.

Inicialmente, al llegar al territorio solo se tenía programada la consolidación de un producto turístico que atacara en parte los rezagos de la crisis de 2016, no obstante, conocer a los participantes, ver las iniciativas del sector privado y conocer a fondo la potencialidad del destino, llevó a considerar un trabajo mucho más extenso y conglomerado desde la formulación hasta su promoción. Cada proceso vinculó tanto a la localidad como a agentes externos que aportaron tanto sus conocimientos como su experticia en el desarrollo de la actividad, permitiendo a los mismos prestadores y habitantes conocerse entre ellos y visibilizarse como un Consejo Provincial de Turismo, organizado desde el trabajo en equipo, demostrando que el turismo funciona como ese eje articulador en las comunidades. 
La incidencia que tiene pensar estratégicamente en el turismo es fundamental, el sector requiere de trazabilidad en sus planes donde la visión a largo plazo articule las necesidades de los sectores involucrados desde la realidad de los mismos. Un ente gestor juega un rol fundamental en la articulación del destino, en este caso, la conformación y participación del Consejo Provincial de Turismo permitió a los actores clave ser parte integral en la gestión de su propio desarrollo por medio de procesos de construcción colectiva.

Lo anterior permite identificar que, para la creación de redes de trabajo en el sector turístico todos tienen un rol que cumplir. Los empresarios, entidades públicas, entidades privadas, entidades mixtas y la academia tienen un reto fundamental para el logro de objetivos comunes a favor del destino y es el de unir voluntades, apoyando en gran medida a fortalecer la capacidad de entender y adaptarse al cambio de manera mancomunada, pues el momento histórico por el que atraviesa la actividad turística genera un proceso de evaluación y aprendizaje, pero también de incertidumbre en el cual es fundamental tener voluntad de seguir avanzando.

Entre la proyección a futuro, parte de la iniciativa obedece a la creación de un Clúster, estrategia que se complementa con una serie de objetivos que, gracias a estos proyectos realizados en la zona, facilitarían la consolidación de dicha organización. Como parte de la estrategia, se privilegia la inclusión de tecnologías de innovación y desarrollo que facilitan la venta y promoción del destino, por ejemplo, por medio de pagos en línea y plataformas digitales.

Por último, sin salir de la línea estratégica, este ejercicio es una invitación para mejorar los procesos que permitan generar mayor impacto positivo en el desarrollo de la actividad turística como actividad seria y planificada, de forma empresarial es fundamental dar mayor relevancia al uso de metodologías de innovación para el sector turístico que no requieren conocimiento científico para la personalización del nuevo turismo, haciendo énfasis en el uso de experiencias de clientes, la inclusión de procesos de mejora continua, planificar, hacer, actuar, diseño de modelos de negocio, creación de planes de mercadeo, aspectos que son necesidades latentes para incursionar en reinvención del turismo.

Este documento y los respectivos proyectos se realizaron gracias al apoyo de las Cámaras de Comercio de Duitama y Bogotá quienes facilitaron los recursos para la labor de los investigadores por medio de las siguientes ordenes: Orden de prestación de servicios independientes N. ${ }^{\circ}$ 025-2017, Diseño del producto turístico para la provincia de Gutiérrez del departamento de Boyacá; Orden de prestación de servicios N. ${ }^{\circ} 6200007613$ /2017, Caracterización de los prestadores de servicios turísticos presentes en la Provincia de Gutiérrez Departamento de Boyacá; Orden de prestación de servicios independientes N. ${ }^{\circ}$ 016-2019, Diseño de un plan de marketing tradicional que aporte al fortalecimiento de la promoción de la oferta turística de la provincia de Gutiérrez en el departamento de Boyacá y Orden de prestación de servicios N. ${ }^{\circ}$ 036-2019, Diseño de un plan de marketing digital para el fortalecimiento de la oferta turística de la provincia de Gutiérrez en el departamento de Boyacá. 


\section{Conflicto de intereses}

Los autores no tienen conflicto de intereses con el contenido de este trabajo.

\section{Contribución de autoría}

SMSC: Diseño y elaboración del manuscrito, recolección y análisis de datos apartado El destino desde la provincia y Producto turístico desde el enfoque territorial. formulación y redacción del diseño de producto, formulación y redacción caracterización de prestadores. Revisión inicial de documento.

A 0 SS: Diseño y elaboración del manuscrito, recolección y análisis de datos apartado Plan de Mercadeo con enfoque en el destino. recolección de datos diseño de producto, recolección de datos y análisis estadístico de caracterización de prestadores. Revisión final de documento.

\section{Referencias}

Buitrago, V. M. (2016). Provincias de Boyacá. Geografía Cultural de Boyacá. Recuperado el 10 de marzo de 2017 de http://www. boyacacultural.com/

Cámara de Comercio de Duitama. (2018). Estudio de mercados, con enfoque de la demanda turística de producto turístico diseñado para el entorno de la Sierra Nevada del Cocuy, Güican de la Sierra y Chita. CCD Duitama.

Castro, A., Mercado, L. A., Londoño, M. Á., y Hoyos, A. D. (2017). Plan de marketing para el posicionamiento regional universitario: Caso Universidad Pontificia Bolivariana Seccional Palmira. Revista Saber, Ciencia y Libertad, 12(2), 233-247. https://doi. org/10.18041/2382-3240/saber.2017v12n2.1592.

CEPAL. (2016). Las provincias de Colombia. En J. C. Ramírez y J. M. De Aguas, Configuración territorial de las provincias en Colombia (pp. 11-17). https://www.cepal.org/sites/default/files/news/files/configuracion_territorial_de_las_provincias_de_colombia.pdf

Comisión Europea de Turismo y Organización Mundial de Turismo. (2013). Manual de desarrollo de productos turísticos. OMT.

Fernández, V. (2006). El producto turístico desde el enfoque de desarrollo territorial. MINCIT.

Gimenéz, G. (1999). Territorio, cultura e identidades: La región socio-cultural. Estudios sobre las Culturas Contemporáneas, 5(9), 25- 57.

Granados, R. H. y Suárez, J. F. (2018). Guía para la caracterización de prestadores de servicios turísticos - Un aporte al desarrollo turístico local. Editorial Uptc.

Hiernaux-Nicolas, D. (2002). Turismo e imaginarios. En F. L. Sociales, Imaginarios sociales y turismo sostenible (pp. 7- 36). FLACSO.

Kotler, P., Bowen J. T., Makens, J. C., García de Madariaga, J. y Flores, J. (2011). Marketing Turístico (5. a ed.). Pearson Educación S.A.

La pelea por El Cocuy. (2017, 13 de enero). Controversia. La pelea por El Cocuy. Semana https://www.semana.com/nacion/articulo/ cierre-del-parque-natural-el-cocuy/512088

Ministerio de Comercio, Industria y Turismo (MINCIT). (2018). Turismo: El propósito que nos une 2018-2022 [Plan Sectorial de Turismo]. MINCIT.

Ministerio de Comercio, Industria y Turismo (MINCIT). (2020). Ley 2068 de 2020 por la cual se modifica la Ley General de Turismo Ley 300 de 1996. MINCIT.

Ministerio de Comercio, Industria y Turismo (MINCIT) y Grupo Planificación y Gestión del Turismo. (2006). Asistencia Técnica en Planificación del Turismo. MINCIT.

Ochoa, F. F. A. y Morales, D. (2016). Tejiendo el territorio, Lineamientos para la construcción del turismo desde lo local. Universidad Externado de Colombia. 
Ojeda, D. y Mármol, P. (2016). Marketing Turístico (Vol. 2). Paraninfo S.A.

Organización Mundial del Turismo. (2019). La cadena de valor del turismo gastronómico. En O. M. (BCC), Guía para el desarrollo del Turismo Gastronómico (pp. 15-18). https://www.e-unwto.org/doi/book/10.18111/9789284420995

Osterwalder, A. y Pigneur, Y. (2010). Business Model Generation: A Handbook for Visionaries, Game Changers, and Challengers. Strategyzer Series.

Sistema de Información para la Artesanía Siart. (2016, 1 de abril). Colombia Artesanal: Guacamayas, una técnica artesanal que enamora. Artesanías de Colombia. http://artesaniasdecolombia.com.co/PortalAC/Noticia/colombia-artesanal-guacamayasuna-tecnica-artesanal-que-enamora_7558

Tunja. \$20.000 millones se han perdido desde el cierre de "El Cocuy". (2017, 24 de marzo). Caracol Radio. https://caracol.com.co/ emisora/2017/03/24/tunja/1490361320_856702.html

\section{Sandra Milena Sanchez Castellanos}

Magister en Planificación y Gestión del Turismo de la Universidad Externado de Colombia, Administradora Turística y Hotelera de la Universidad Pedagógica y Tecnológica de Colombia, Facultad Seccional Duitama. Docente Investigadora de la Corporación Unificada Nacional de Educación Superior y cofundadora del OTGUIA Observatorio Turístico de la Universidad Pedagógica y Tecnológica de Colombia.

sandra_sanchezc@cun.edu.co

ORCID: https://orcid.org/0000-0002-5204-8351

José Fabián Suarez Salazar

Especialista en Gestión Estratégica de Proyectos de la Universidad Pedagógica y Tecnológica de Colombia Facultad Seccional Duitama, Administrador Turístico y Hotelero de la Universidad Pedagógica y Tecnológica de Colombia Facultad Seccional.

josefabian.suarez@uptc.edu.co 